\title{
COMPARISON OF ORAL CHLOROQUINE WITH SYSTEMIC MEGLUMINE ANTIMONIATE IN TREATMENT OF CUTANEOUS LEISHMANIASIS
}

\author{
Muhammad Farooq, Muhammad Saad Farooq*, Arfan Ul Bari**, Tariq Mehmood Malik*** \\ Combined Military Hospital Peshawar/National University of Medical Sciences (NUMS) Pakistan, *Nishtar Hospital, Multan Pakistan, \\ **Pakistan Naval Ship Shifa Hospital, Karachi/National University of Medical Sciences (NUMS) Pakistan, Combined Military Hospital \\ Bahawalpur/National University of Medical Sciences (NUMS) Pakistan
}

\begin{abstract}
Objective: To compare the efficacy of oral chloroquine with systemic meglumine antimoniate in treatment of cutaneous leishmaniasis.

Study Design: Open-label comparative prospective study.

Place and Duration of Study: Study was conducted in the department of Dermatology, Combined Military Hospital Multan, from Jan to Oct 2018.

Methodology: Fifty adult male patients completed the study. The inclusion criteria for the study were patients having untreated skin lesions less than 3 months old. Diagnosis was made on the basis of history and clinical features and was confirmed on histopathological examination. Patients were divided into 2 groups of 25 each, group A patients received meglumine antimoniate $810 \mathrm{mg}$ intramuscularly once a day whereas group B patients were given oral chloroquine $250 \mathrm{mg}$ twice a day. Pre-treatment complete physical examination was done along with blood complete picture, urine routine examination, liver function tests, renal function tests and electrocadiogram. They were repeated after 2 weeks and at the end of treatment. The efficacy was measured by healing of lesions with a measuring tape.

Results: Fifty patients completed the study. At the end of treatment, among group A patients, 4 (16\%) showed no improvement, 21 (84\%) improved; whereas in group B patients, $11(44 \%)$ showed no improvement, 14 (56\%) showed improvement. Percentage reduction in surface area of skin lesions was $77.6 \%$ in group A, whereas in group B, it was $42.7 \%$.

Conclusion: Meglumine antimoniate showed better efficacy than chloroquine but oral chloroquine was also effective and can be used as an alternative therapy.
\end{abstract}

Keywords: Chloroquine, Leishmaniasis, Meglumine antimoniate, Pentavalent antimonial.

This is an Open Access article distributed under the terms of the Creative Commons Attribution License (http://creativecommons.org/licenses/by/4.0), which permits unrestricted use, distribution, and reproduction in any medium, provided the original work is properly cited.

\section{INTRODUCTION}

Leishmaniasis, an ancient disease was named after W. B. Leishman, who identified organisms in smears taken from the spleen of a patient who died from visceral leishmaniasis in $1901^{1}$. It is a protozoal disease transmitted by sandfly. There are several species of vector, each occupying a particular zoogeographical zone. The disease is endemic in 88 countries, 72 of which are developing countries, most commonly in tropical and subtropical regions ${ }^{2}$. Clinical manifestations of the disease range from aggressive cutaneous ulcers to systemic multi-organ disease. The

Correspondence: Dr Muhammad Farooq, Dept of Dermatology, Combined Military Hospital, Peshawar Pakistan

Received: 24 Aug 2019; revised received: 24 Nov 2019; accepted: 25 Nov 2019 skin lesions of the disease and the scars left after healing cause significant morbidity and demoralizing effect on patients. The treatment with meglumine antimoniate often requires hospitalization resulting in wastage of manpower besides its financial implications.

The disease burden remains significant in twenty-first century, with a world prevalence of 12 million and an annual incidence of two million cases $^{3}$. The world health organization classified leishmaniasis as a category I disease (emerging and uncontrolled) $)^{4}$.

In Pakistan, both zoonotic and anthroponotic cutaneous leishmaniasis (CL) are endemic in most parts of the country. The anthroponotic form is found mostly in urban areas while 
zoonotic form is widespread over a large area of Baluchistan particularly in Sibi, Lehri, Kohlu, Dera Bugti, Dera Murad Jamali, Duki, Lorali, and Khuzdar ${ }^{5-7}$.

Cutaneous leishmanisis (CL) is a major health problem amongst the military troops stationed in various areas of Pakistan, as majority of them are from non-endemic areas and represent a large group of susceptible population. Epidemics occur when fresh troops move into the endemic area.

Most sores heal spontaneously but in view of prolonged duration of disease and disfiguring resultant scars, it is imperative to offer treatment to all individuals suffering from CL. At present, different treatment options are available, but unfortunately none has proved ideal, simulaneously safe, effective, affordable treatment. Pentavalent antimonials still remain the mainstay of treatment in the majority of cases. However, these have the disadvantage of both toxicity and clinical resistance in at least $40 \%$ of cases in certain regions. Other treatment options are Imidazole compounds and Pentamidine, given systemically. Drugs such as Allopurinol, Rifampicin, Dapsone, Chloroquine, Nifurtimox have also shown improvement in some studies 8,9 .

Chloroquine is an antiprotozoal drug and has much less side effects and cost compared to antimony compounds. It is widely used orally as an antimalarial. Being antiprotozoal, we thought it worthwhile to compare the efficacy of this cost effective drug with the current standard therapy pentavalent antimonials in CL.

\section{METHODOLOGY}

A comparative prospective study, comparing the efficacy of injectable pentavalent antimonial meglumine antimoniate and oral chloroquine was carried out in dermatology department of Combined Military Hospital Multan from Jan 2018 to Oct 2018. Ethics approval was sought from IERB, vide $\mathrm{CMH}$ Multan certificate dated 1 Jan 2018. Fifty two patients were enrolled in the study, but 50 were available at the end of treatment. Two were dropped due to side effects of treatment. The sample size was calculated by using the software Open Epi, as it was done in a study conducted by Fahmida et al at Sheikh Zayed Hospital Rahim Yar Khan ${ }^{16}$. Informed consent was obtained from every patient before inclusion in the study. All the patients were adult males ranging from 19-64 years. The patients were referred from three provinces - Punjab, Baluchistan, and KPK to CMH Multan. They were admitted in skin ward. The inclusion criteria for the study were patients having lesions less than 3 months old and not treated for cutaneous leishmaniasis, age more than 12 years and both genders. The patients were excluded from the study if lesions were older than 3 months or if they were given any local or systemic antileishmaniasis treatment, and patients having other significant concomitant disease like endstage renal and hepatic disease.

Patients were clinically diagnosed on the basis of history of origin and nonhealing painless skin lesions suggestive of cutaneous leishmaniasis. The clinical diagnosis was confirmed by microscopic examination of slit-skin smear for Leishmania Trophozoite bodies (LT bodies) or skin biopsy for histopathology from skin lesions ${ }^{11}$. After confirmation of diagnosis, informed consent was taken. The lesions were measured using measuring tape. Blood Complete picture, urine routine examination, Electrocardiogram, liver function tests and kidney function tests were carried out before starting treatment. Electrocardiogram, Blood complete picture and liver function tests were repeated after 2 weeks and at end of treatment.

Fifty two patients fulfilling the inclusion criteria were enrolled in the study by nonprabability consecutive sampling. They were divided into two groups A and B randomly by Lottery system. Group A patients received megluminea ntimoniate intramuscularly in a dose of $810 \mathrm{mg} /$ day for 28 days while group B patients received chloroquine treatmentorally in a dose of $250 \mathrm{mg}$ twice a day for 28 days. Efficacy was measured clinically by healing of skin lesions i.e. reduction in induration of erythematous and crusted plaq- 
ues, ulcer healing and re-epitheliazation in case of ulcerated lesions. SPSS version 21 was used for data analysis. Quantitative data was presented with mean and standard deviation. Qualitative data was presented with frequencies and percentages. A $p$-value $\leq 0.05$ was considered significant.

\section{RESULTS}

A total of 52 patients were enrolled in the study; all were adult otherwise healthy military male soldiers. There were 25 patients in group A, side effects of treatment i.e. fever, severe nausea and vomiting, so a total of 50 patients completed the study. Group A patients had a mean age \pm SD of $25.72 \pm 4.61$ years while group B patients had a mean age and standard deviation of $26.44 \pm 8.95$ years. The patients belonged to 3 provinces of Pakistan (table-I). The morphology of skin lesions varied from erythematous plaques, crusted plaques to ulcerated plaques (table-I). At the end of treatment, among group A patients, 4 (16\%) showed no improvement, 21 (84\%) improved; where-

Table-I: Demographic data of study participants.

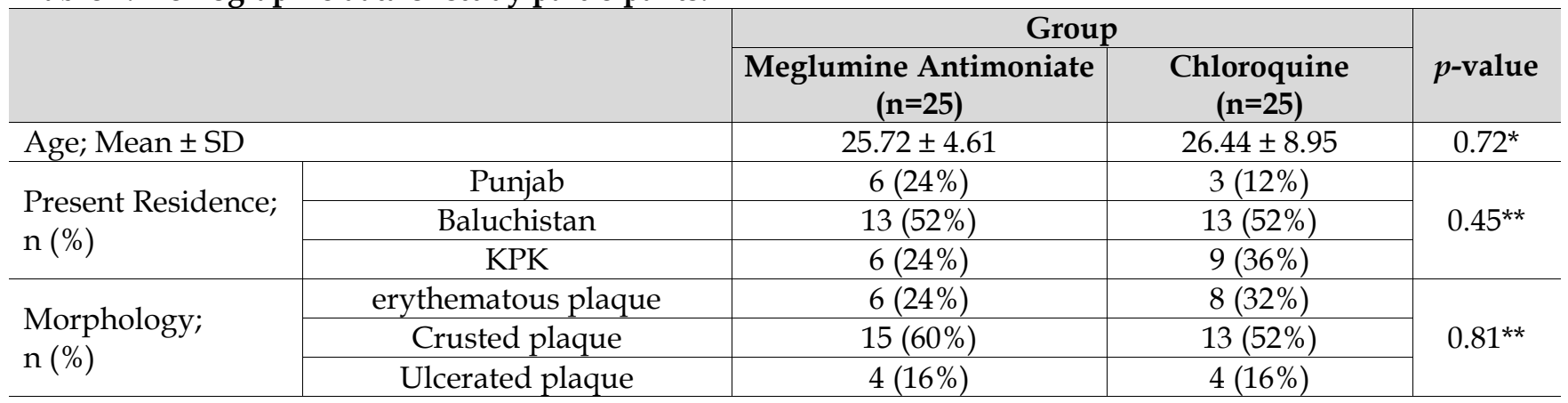

*Independent sample t-test, ${ }^{* *}$ Chi-square test

Table-II: Association of response treatment and response category with reference to treatment groups.

\begin{tabular}{|c|c|c|c|c|}
\hline & \multirow{2}{*}{\multicolumn{2}{|c|}{ Group }} & \multirow[b]{3}{*}{$p$-value } \\
\hline & & & & \\
\hline & & $\begin{array}{c}\text { Meglumine } \\
\text { Antimoniate }(n=25)\end{array}$ & $\begin{array}{c}\text { Chloroquine } \\
(n=25)\end{array}$ & \\
\hline \multirow{5}{*}{$\begin{array}{l}\text { Response to } \\
\text { treatment } \\
\mathrm{n}(\%)\end{array}$} & No response $(0 \%-20 \%)$ & $3(12 \%)$ & $6(24 \%)$ & \multirow{5}{*}{$0.350^{* *}$} \\
\hline & Mild Response (20.1-40\%) & - & $2(8 \%)$ & \\
\hline & Moderate Response (40.1-60\%) & $1(4 \%)$ & $2(8 \%)$ & \\
\hline & Good Response (60.1-80\%) & $5(20 \%)$ & $3(12 \%)$ & \\
\hline & Excellent Response (80.1-100\%) & $16(64 \%)$ & $12(48 \%)$ & \\
\hline \multirow{2}{*}{$\begin{array}{l}\text { Response } \\
\text { Category, n (\%) }\end{array}$} & No Improvement & $4(16 \%)$ & $11(44 \%)$ & \multirow{2}{*}{$0.030^{* *}$} \\
\hline & Improved & $21(84 \%)$ & $14(56 \%)$ & \\
\hline
\end{tabular}

${ }^{* *}$ Chi square test

Table-III: Mean surface area difference within treatment groups.

\begin{tabular}{|c|c|c|c|}
\hline \multicolumn{2}{|l|}{ Group } & Mean Rank & $p$-value \\
\hline \multirow{4}{*}{$\begin{array}{l}\text { Meglumine } \\
\text { Antimoniate }\end{array}$} & Surface area involved $\left(\mathrm{cm}^{2}\right) \_$start & 2.84 & \multirow{3}{*}{$0.001^{*}$} \\
\hline & Surface area involved $\left(\mathrm{cm}^{2}\right) \_2$ weeks & 1.94 & \\
\hline & Surface area involved $\left(\mathrm{cm}^{2}\right)$ end of treatment (4 weeks) & 1.22 & \\
\hline & Percentage reduction in surface area & $77.6 \%$ & \\
\hline \multirow{4}{*}{ Chloroquine } & Surface area involved $\left(\mathrm{cm}^{2}\right) \_$start & 2.48 & \multirow{3}{*}{$0.001^{*}$} \\
\hline & Surface area involved $\left(\mathrm{cm}^{2}\right) \_2$ weeks & 2.20 & \\
\hline & Surface area involved $\left(\mathrm{cm}^{2}\right)$ end of treatment (4 weeks) & 1.32 & \\
\hline & Percentage reduction in surface area & $42.7 \%$ & \\
\hline
\end{tabular}

${ }^{*}$ Friedman test (non-parametric test) for non-normal data distribution.

whereas group B contained 27 patients. In group B, 2 patients were excluded from the study due to as in group B, $11(44 \%)$ showed no improvement, $14(56 \%)$ showed improvement (table-II). Percen- 
tage reduction in surface area of skin lesions was $77.6 \%$ in group $\mathrm{A}$, whereas in group $\mathrm{B}$, it was $42.7 \%$ (table-III).

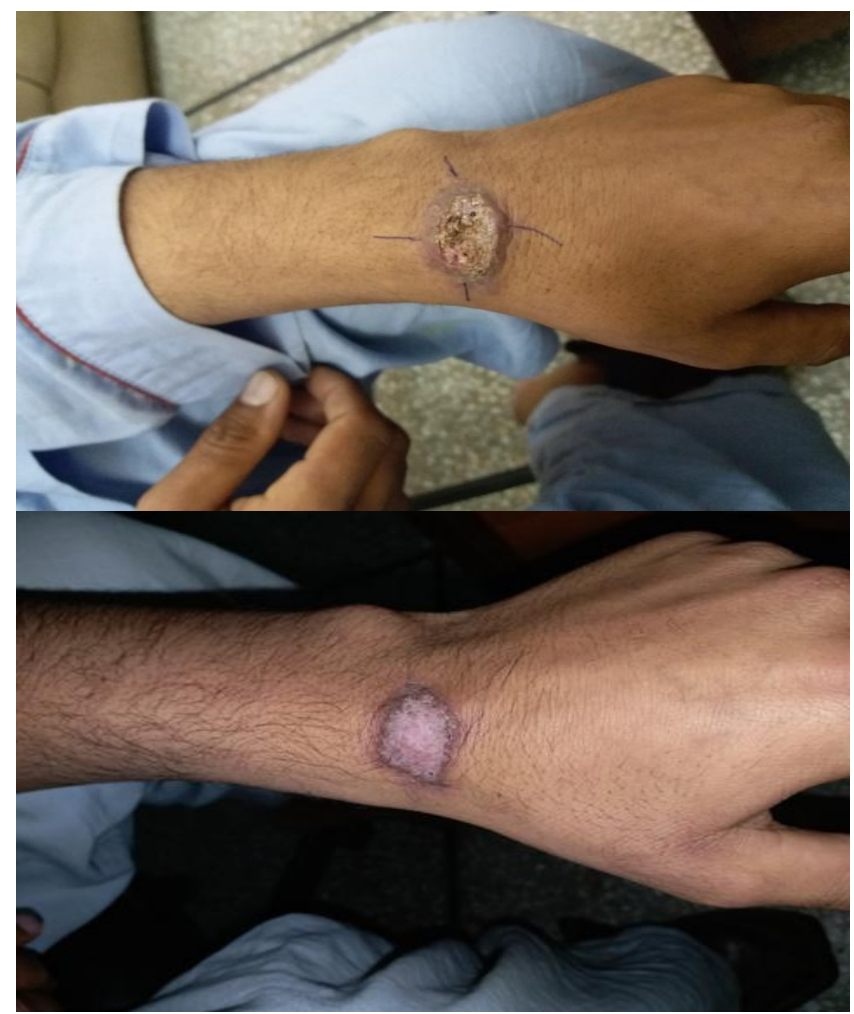

Figure-1: Cutaneous Leishmaniasis before treatment (left), after treatment with meglumine antimoniate (right).

\section{DISCUSSION}

Cutaneous leishmaniasis is a fairly common disease worldwide and endemic in several areas of Pakistan throughout the country. The mainstay of treatment for this condition are antimonials, these compounds have the disadvantage of availability issues, high cost, toxicity and clinical resistance. Chloroquine is an antiprotozoal drug which is used as an antimalarial. Our study was planned to find out the efficacy of chloroquine and to compare the results with antimonial compounds. The study showed that both are effective in cutaneous leishmaniasis but meglumine antimoniate was better than choroquine in treatment of cutaneous leishmaniasis, which was in contrast to a study conducted at Pakistan Institute of medical Sciences Islamabad in 2006-200710, which showed a cure rate of $100 \%$ in Chloroquine group and $93 \%$ in antimony groupat the end of treatment, though their duration of treatment was 20 days versus 28 days in our study. Another study

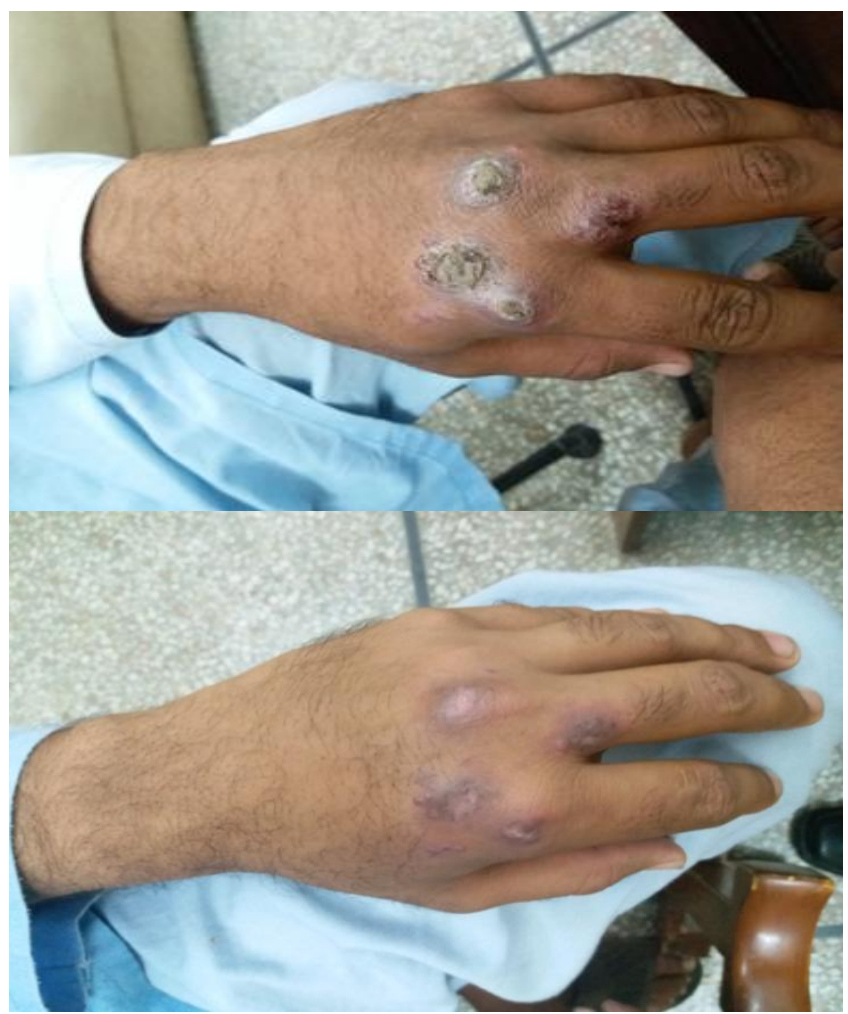

Figure-2: Cutaneous Leishmaniasis before treatment (left), after treatment with chloroquine (right).

conducted at Sheikh Zayed Hospital Rahim Yar Khan, comparing the efficacy of oral chloroquine with intralesional chloroquine found oral chloroquine $100 \%$ curative with a mean duration of treatment $11.37 \pm 3$ weeks ${ }^{12}$. However, in this stu$\mathrm{dy}$ the dose of oral chloroquine was $250 \mathrm{mg}$ daily. A study conducted by Mashhood et al at PNS Shifa Karachi compared the efficacy of Allo-purinol with antimony compound Pentostam ${ }^{13}$. The patients were given either antimony compound Pentostam or oral Allopurinol for 2 weeks. At the end of treatment, $85 \%$ of patients on Pentostam cured whereas $70 \%$ of patients on Allopurinol got cured.

There are other studies which compare the efficacy of oral chloroquine with oral tetracycline ${ }^{15,16}$. In the study conducted at Sheikh Zayed Hospital Rahim Yar Khan, the patients were given oral chloroquine $250 \mathrm{mg}$ twice a day or oral 
doxycycline $200 \mathrm{mg}$ per day for 3 months. At the end of treatment, $100 \%$ patients of chloroquine group cured but $92 \%$ patients on doxycycline cured $^{16}$. Fluconazole has also been used to treat cutaneous leishmaniasis ${ }^{17,18}$. In the study, conducted in Saudi Arabia caused by Leishmania major, oral fluconazole was given $200 \mathrm{mg}$ per day for 6 weeks. At the end of treatment, $79 \%$ patients were cured compared to $34 \%$ in placebo group ${ }^{17}$. A study by Skina et al at Pak Emirates Military Hospital Rawalpindi comparing the efficacy of meglumine antimoniate with oral zinc concluded that oral zinc was not better than meglumine antimoniate ${ }^{19}$. There were other studies which compare the efficacy of meglumine antimoniate with other therapeutic modalities ${ }^{22-25}$. A study conducted by Bilal et al in Quetta city to see the effects of combined therapy of meglumine anti-moniate and cotrimoxazole in CL concluded that this combination is better than the previously reported combined therapies 22 .

\section{LIMITATIONS OF STUDY}

As the study was conducted in military setup, all the patients were young adult males except one who was retired (64 years). There was no female patient. All the patients were treated indoor, as they came from remote areas. They were discharged at the end of treatment. It was difficult to follow the patients post treatment, as they were deployed at various stations at farflung areas. As there was difference in efficacy of oral chloroquine in this study compared to previous ones, further studies are required to elaborate this difference.

\section{CONCLUSION}

systemic antimonials showed better efficacy for the treatment of Cutaneous Leishmaniasis compared to oral chloroquine though the difference was not significant. So oral chloroquinemay be a good second line choice in cases not tolerating antimony compounds and in cases where they were not available or were contraindicated.

\section{CONFLICT OF INTEREST}

This study has no conflict of interest to be declared by any author.

\section{REFERENCES}

1. Malek JM, GhosnSH. Leishmaniasis and Other Protozoan Infections. In: K. Wolff and L. Goldsmith eds, Fitzpatrick's Dermatology in General Medicine, 8th ed. New York: McGraw-Hill: 2012; 2527-37.

2. Downing, C. Tyring, S. Parasitic Diseases. In: Griffiths C, Parker J, Bleiker T, eds. Rook's Textbook of Dermatology, 9th ed. London: John Wiley \& Sons: 2012; 40-48.

3. Desjeux P. Leishmaniasis: Current situation and new perspectives. Comp Immunol Microbiol Infect Dis 2004; 27(5): 305-18.

4. World Health Organisation. Weekly epidemiological record No. 44 2002; 77: 365-72. Available from: https://www.who.int/ docstore/wer/pdf/2002/wer7744.pdf

5. Bhutto AM, Soomro RA, Nonaka S, Hashiguchi Y. Detection of new endemic areas of cutaneous Leishmaniasis in Pakistan: A 6year study. Int J Dermatol 2003; 42(7): 543-48.

6. Ayub S, Gramiccia M, Khalid M, Mujtaba G, Bhutta RA. Cutaneous leishmaniasis in Multan: species identification. J Pak Med Assoc 2003; 53(10): 445-47.

7. Khan NH, Bari AU, Hashim R, Khan I, Muneer A, Shah A, et al. Cutaneous Leishmaniasis in Khyber Pakhtunkhwa Province of Pakistan: Clinical Diversity and Species-Level Diagnosis. Am J Trop Med Hyg 2016; 95(5): 1106-14.

8. Lee SA. Hasbun R. Therapy of cutaneous leishmaniasis. Int J Infect Dis 2003; 7 (2): 86-93.

9. Davies CR, Kaye P, Croft SL, Sundar S. Leishmaniasis: new approaches to disease control. Brit Med J 2003; 326 (7385): 377-82.

10. Khan I,Yasmin R, Siddiqui I. Chloroquine in cutaneous leishmaniasis. J Pak Med Assoc 2007; 17(2): 95-100.

11. Mashhood AA, Khan IM, Nasir S, Agha H, Saleem M, Imran A. Fine needle aspiration cytology versus histopathology in the diagnosis of cutaneous leishmaniasis in Pakistan. J Coll Physicians Surg Pak 2005; 15(2): 71-73.

12. Hanif MM, Akram K, Mustafa G. Intralesional versus oral chloroquine in cutaneous leishmaniasis: Comparison of out-come, duration of treatmentand total dose of drug. J Coll Physicians Surg Pak 2016; 26(4): 260-62.

13. Mashhood AA, Hussain K. Efficacy of Allopurinol compared with Pentostam in the treatment of Old World cutaneous leishmaniasis. J Coll Physicians Surg Pak 2001; 11(6): 367-70.

14. Astelbauer F, Walochnik J. Antiprotozoal compounds: state of the art and new developments. Int J Antimicrob Agents 2011; 38(2): 118-24.

15. Masmoudi A, Dammak A, Chaaben H, Maalej N, Akrout F, Turki H. Doxycycline for the treatment of cutaneous leishmaniasis. Dermatol Online J 2008; 14(8): 22.

16. Fehmida M, Hanif MM, Mustafa G. Comparing the efficacy of oral chloroquine versus oral tetracycline in the treatment of cutaneous leishmaniasis. J Coll Physicians Surg Pak 2019; 29(5): 403-05.

17. Alrajhi AA, Ibrahim EA, Devol EB. Fluconazole for the treatment of cutaneous leishmaniasis caused by Leishmania major. $\mathrm{N}$ Eng J Med 2002; 346(12): 891-95.

18. Zvulonov A, Klaus S, Vardy D. Fluconazole for the treatment of cutaneous leishmaniasis. N Eng J Med 2002; 347(5): 370-71.

19. Malik SS, Iftikhar N, Minhas IJ, Tahir M. Comparison of efficacy of oral zinc sulphate with intramuscular meglumine antimoniate in patients of cutaneous leishmaniasis. Pak Armed Forces Med J 2016; 66(1): 39-43.

20. Tahir M, Bashir U, Hafeez J, Ghafoor R. Safety and efficacy of miltifosine in cutaneous leishmaniasis: an open label, noncomparative study from Baluchistan. Pak J Med Sci 2019; 35 (2): 495-99. 
21. Shah SA, Memon AA, Shamim A, Baqi S, Witzig R. Low-cost thermotherapy for cutaneous Leishmaniasis in Sind, Pakistan. J Pak Med Assoc 2014; 64(12): 1398-404.

22. Ahmed B, Tareen MI, Kumar A, Baloch S, Hazir R, Mustafa Z. An effective combined therapy of meglumine antimoniate and co-trimoxazole for cutaneous leishmaniasis: A study in Quetta City. J Pak Assoc Derm 2014; 24(2): 122-26.

23. Dilnawaz M, Hussain K, Malik NJ, Khan LM, Mazhar H, Soomro AA. Clinical audit on treatment of mucosal and multiple cutaneous leishmaniasis lesions with pentavalent systemic anti- mony. J Pak Assoc Derm 2015; 25(1): 40-43.

24. Ejaz A, Qadir SNR, Malik N, Bari AU. Comparison of low-dose meglumine antimoniate/ allopurinol combination therapy with full dose meglumine antimoniate alone in the treatment of cutaneous leishmaniasis - a randomized controlled trial. J Pak Assoc Derm 2014; 24(2): 108-14.

25. Bhatti MZ, Noor SM, Paracha MM, Ullah G. Efficacy of combined intralesional meglumine antimoniate and cryotherapy versus cryotherapy alone for the treatment of cutaneous leishmaniasis. J Postgrad Med Inst 2018; 32(1): 103-06. 